\title{
EMERGENCIES IN GENERAL PRACTICE
}

\section{ACUTE HEPATIC FAILURE}

\author{
BY \\ SHEILA SHERLOCK, M.D., F.R.C.P. \\ Physician and Lecturer, Postgraduate Medical School of London
}

"Wandering and uncertain shiverings ... follows
a most fatal putrefaction of that noble entrail."

-BoerhaAve (1742).

Failure of liver-cell function may occur suddenly with deep coma, or its onset may be insidious and associated with a perplexing combination of mental and neurological signs. In either category its early recognition is important because it is often reversible and its recurrence can be anticipated and prevented.

The features common to all forms of acute hepatic failure are cerebral changes, fetor hepaticus, and mild fever.

The cerebral changes are diffuse, and all parts of the central nervous system may be involved. Mental disturbances are the most conspicuous ; change in personality, confusion, mania, and sometimes screaming are followed by stupor and eventually coma ("hepatic coma ") resembling a deep sleep. Disordered motor activity is shown by the "flapping" tremor reminiscent of the beating of a bird's wings. When the patient holds his arms in front of him with his fingers separated, rapid irregular movements occur in bursts, with flexion extension of the wrists and metacarpo-phalangeal joints. There is also a fine 6-9-per-second tremor of the outstretched hands. The movements disappear in repose and are apt to be overlooked if the patient is observed only at rest and not asked to hold his hands in front of him.

Fetor hepaticus is a sweet, slightly faecal odour detected in the breath. It has been likened to the smell of mice or to a freshly opened corpse. It is of intestinal origin.

The temperature may be raised to $100-101^{\circ} \mathrm{F}$. (37.8$38.3^{\circ} \mathrm{C}$.).

The two commonest causes of acute hepatic failure are acute virus hepatitis and portal cirrhosis of the liver.

\section{-}

\section{Virus Hepatitis}

Of the patients with virus hepatitis, $99.8 \%$ recover uneventfully. The unfortunate complication of severe livercell necrosis is therefore rare and correspondingly difficult to recognize.

In the jaundiced patient mental disturbance provides the earliest warning of this grave turn of events. The patient becomes disorientated, confused, and rambling. Fetor hepaticus and the flapping tremor are present. Jaundice is deep, and persistent vomiting is a bad sign. The temperature rises. Daily percussion of hepatic dullness reveals shrinking of the liver under the right costal margin. Ascites may be present if the illness is of longer than two to three weeks' duration.

Acute hepatic failure can also occur early in the course of virus hepatitis, and is then extremely difficult to diagnose, for jaundice is inconspicuous or absent. The predominant clinical features are mental, and the patient may be admitted to a mental hospital without the hepatic disease being recognized. Helpful diagnostic points are a history of epidemic jaundice in the community or recent injection therapy giving the opportunity for transmission of the hepatitis virus. There is anorexia, the liver edge is tender, and percussion over the right lower ribs posteriorly causes sickening right upper quadrant abdominal pain. The urine contains bilirubin, but sensitive tests may be needed to demonstrate it. Fouchet's method or the new tablet test are equally satisfactory.

\section{Portal Cirrhosis}

When hepatic failure complicates chronic portal cirrhosis it is important to know why it has developed. An effort must be made to determine any factor which has depressed the liver function. Gastro-intestinal haemorrhage may have occurred from oesophageal varices, and evidence of haemorrhage must be sought. The bleeding is often slow and occult, and melaena may be detected only by rectal examination. Acute infections such as pneumonia, minor surgical operations such as paracentesis abdominis, and acute alcoholism are other possible precipitants.

When mental or neurological changes complicate welldocumented cases of portal cirrhosis, the problem of recognition of the syndrome should not be difficult. Episodes of confusion, flapping tremor of the hands or arms, fetor hepaticus, or stupor can be detected by careful examination. Indeed, if the portal cirrhosis is well recognized, it is difficult to know what else could cause this strange, episodic, neurological picture. Difficulty in diagnosis arises when cirrhosis has not been considered as the underlying cause and the patient is believed to be suffering from one of the other organic dementias, arising from conditions such as cerebral atherosclerosis, cardiac failure, uraemia, Parkinsonism, and disseminated sclerosis, or from the abuse of drugs. The recognition of the underlying cirrhosis, therefore, becomes the key to the diagnostic problem. A history of alcoholism or previous jaundice should be sought, and clinical features of cirrhosis such as mild jaundice, spider naevi on the skin, palmar erythema, ascites, distended abdominal wall veins, and enlargement of liver and spleen noted.

Rarely, the neurological changes in the cirrhotic patient are chronic, and episodes of tremor, confusion, stupor, and coma may occur for years before the correct diagnosis is made. This concept of "chronic intermittent hepatic coma" has been recognized only recently. In the intervals between the episodes the patient is almost normal. Deterioration can often be related to increased amounts of nitrogen-containing substances in the intestines and may therefore follow medication with ammonium chloride, methionine or other amino-acids, or even a high protein diet. The relationship of this observation to the treatment of patients with liver disease is discussed later.

\section{Other Causes}

When acute hepatic failure occurs in pregnancy the commonest causes are virus hepatitis and eclampsia. Virus hepatitis of serum type is common in pregnancy because of the many injections performed during antenatal supervision. Cirrhosis is an unlikely diagnosis because patients with chronic liver disease are usually infertile.

Certain poisons cause acute hepatic failure, and suicidal or accidental ingestion of such chemicals as carbon tetrachloride or phosphorus must always be considered. 


\section{Prognosis}

Acute hepatic failure complicating virus hepatitis has a worse outlook than that complicating cirrhosis of the liver. The mortality rate in patients with virus hepatitis and hepatic coma is about $70 \%$. However, the liver possesses such an enormous power of regeneration that even the deeply comatose patient may resume consciousness and ultimately recover completely, with apparently no residual liver damage or shortened expectancy of life. In speaking to the relatives a reasonably hopeful attitude must therefore always be maintained.

The prognosis for acute hepatic failure complicating cirrhosis is very variable and hence difficult to predict. When there has been a clear precipitating factor such as alcoholism or infection the outlook is fairly good because such features can be corrected. When the acute failure follows haemorrhage the prognosis is poor, for the bleeding may be difficult to control.

Insidiously developing hepatic failure in the cirrhotic patient carries a reasonably good prognosis, especially if the patient is not jaundiced and neurological changes can be related to increased amounts of nitrogen in the intestines. With correct dietary management the patients can be maintained in mental equilibrium for years.

\section{Pathogenesis of Acute Liver Failure}

All the clinical features of acute hepatic failure are probably due to absorption into the blood stream of intestinal contents which have not been detoxicated by the liver (see diagram). Normally, the liver acts as a useful intermediary

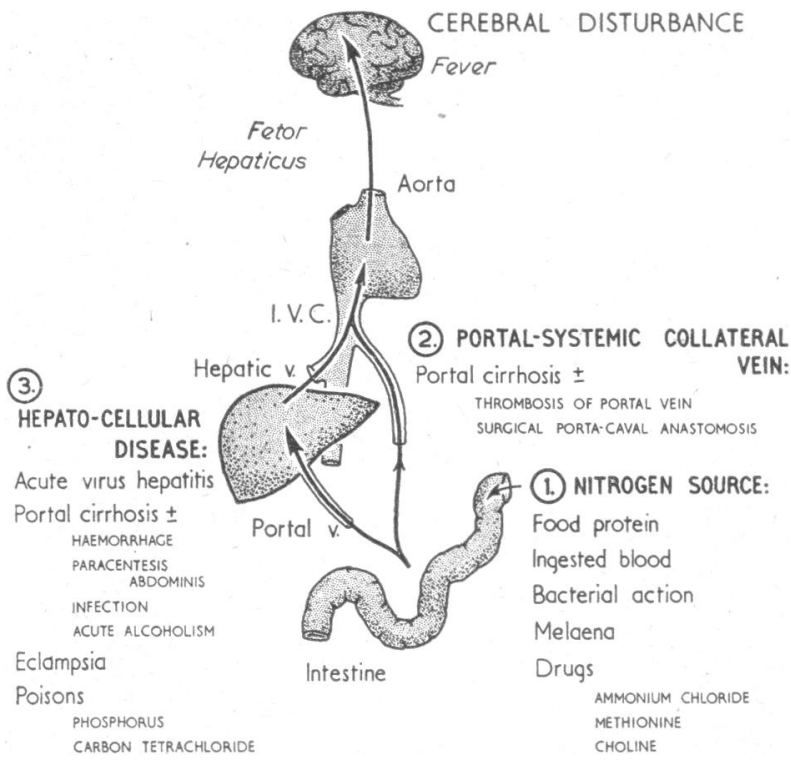

The mechanism of neurological changes leading to hepatic coma (modified from Sherlock, Summerskill, White, and Phear, 1954 Lancet, 2, 453). The three important factors are: (1) Nitrogenous substances in the intestines. (2) Portal-systemic collateral veins diverting blood past the liver. (3) Depressed hepato-cellular function.

filter, which prevents gastro-intestinal poisons reaching the systemic circulation and the brain. The failing liver of hepatitis or cirrhosis is unable to fulfil this function adequately and the by-pass may even be accentuated by the presence of collateral vessels connecting the portal and systemic circulations, as in cirrhosis with portal hypertension. If the portal vein is thrombosed, a not uncommon complication of hepatic cirrhosis, the whole portal blood flow is deviated through collateral channels. Poisons which are apt to gain entrance to the general circulation include bacteria causing pyrexia, various intestinal toxins producing fetor hepaticus, and certain nitrogenous substances causing cerebral disturbance. The actual cerebral poisons present in portal venous blood are unknown, but undesirable effects may follow such nitrogen-containing substances as a highprotein diet, ammonium chloride, urea, methionine, or choline. The portal vein and cerebrospinal fluid contain a high concentration of ammonia in hepatic coma. However, the relation between the neurological changes in man and blood "ammonium" concentration is not close enough to assume that ammonia toxicity is the cause. The patients are not hypoglycaemic and no other constant biochemical abnormality has been demonstrated.

This theory of "auto-intoxication" or portal-systemic encephalopathy may appear to be an old one, but it certainly accounts for many of the clinical features which commonly occur in hepatic failure, and it suggests a regime of management which has proved satisfactory in these patients.

\section{Treatment}

There is little active treatment that can be undertaken before hospital admission. Therefore admission is urgent and should be arranged as soon as the diagnosis is made. It is important to resist the use of drugs which are detoxicated by the liver, because their prolonged and undesirable action may contribute to the coma. Such drugs include morphine and most barbiturates. If the patient is restless and sedation is indicated, paraldehyde may be given per rectum in a dose of $16-20 \mathrm{ml}$. emulsified in $60 \mathrm{ml}$. of normal saline. Otherwise, glucose drinks will suffice as a temporary measure.

The management of the patient in hospital is here given only in outline. The initial care should always be undertaken in an establishment where constant supervision, a suitable dietary regime, and clinical and biochemical assessment of liver-cell function are all available. The basic principles, however, apply equally when the cirrhotic patient is discharged home to the practitioner's supervision.

Treatment in hospital is directed along two lines: (1) eliminating potentially toxic nitrogenous substances from the intestines; and (2) improving hepato-cellular function.

\section{Elimination of Intestinal Intoxicants}

Possible toxic nitrogenous compounds include a highprotein diet, methionine, choline, and ammonium chloride, and these are all avoided. The physician is torn between the policy of a liberal protein diet as a general principle in liver disease and the avoidance of protein because of its potential toxicity. When the patient is first observed, protein should not be given, but he should be maintained for one week on glucose and a little fat. This alone may produce a striking remission of the neurological sequelae and permit more adequate assessment of liver-cell function. Such a protein-free diet can be used only temporarily until symptoms are brought under control; thereafter, protein must be gradually increased. A diet containing $25 \mathrm{~g}$. of protein is introduced for one week, and this should be raised by $25 \mathrm{~g}$. during successive weeks. It is usually found that patients with cirrhosis and chronic neurological complications can tolerate only $50 \mathrm{~g}$. of protein daily. It must not be thought that all patients with cirrhosis of the liver should have such a low-protein diet; it is recommended only for those with neurological complications.

During the initial protein-free period, adequate calorific intake must be maintained, otherwise endogenous protein breakdown produces amino-acids and a further metabolic strain on the liver. So long as the patient remains cooperative 2,000 calories can be administered daily by mouth in the form of $20 \%$ glucose in fruit juices. Should he be uncooperative, it may be necessary to resort to gastric tubefeeding or intravenous infusions. An intragastric tube supplying $20 \%$ glucose in water at a rate of $20-30$ drops a minute provides 2 litres or 1,600 calories during 24 hours ; $1 \mathrm{~g}$. of potassium chloride is added to each litre.

Intravenous feeding is recommended if persistent vomiting or uncooperation makes the intragastric drip method impracticable. In order to provide sufficient calories without 
fluid overload, $20 \%$ glucose in water is employed, 2 litres a day being given. Since this would irritate small veins, with a resulting phlebitis, it is delivered into a large venous channel, such as the innominate vein or superior vena cava, by means of "polythene" tubing. This method ensures continuous intravenous feeding for several days.

Since toxaemia from the effect of intestinal bacteria on nitrogen-containing substances may play a part in the genesis of these changes, temporary sterilization of the gut is worthwhile. It is best to choose a broad-spectrum antibiotic such as chlortetracycline or tetracycline, giving $0.5 \mathrm{~g}$. six-hourly orally, or if necessary by stomach tube, as long as the coma lasts or to a maximum of one week. Parenteral antibiotics are not effective.

After an enema initially, daily motions should be ensured with magnesium sulphate.

\section{Improvement of Hepato-cellular Function}

This implies the energetic treatment of any factor which is depressing liver function and precipitating failure. Infection is treated with antibiotics, anaemia is controlled by blood transfusion, and alcohol is forbidden. A carbohydrate diet allows the maximal metabolic rest to the liver.

Intravenous glutamic acid has been advocated for the treatment of patients with hepatic coma. Wide experience of it in many parts of the world has failed to show any consistent improvement in patients suffering from a condition remarkable for its day-to-day variation.

\section{Results of Treatment}

Any treatment advocated for hepato-cellular failure is difficult to assess, for the cause of the syndrome is uncertain and the clinical state so variable from time to time. Using the above conservative regime, I have treated 21 patients with the syndrome of acute hepatic failure due to virus hepatitis or portal cirrhosis. Two of five patients with virus hepatitis and 11 of 16 with portal cirrhosis have survived episodes of coma.

If the patient with acute virus hepatitis survives acute hepatic failure, recovery is usually complete. The cirrhotic patient, however, is liable to recurrences, and the general practitioner must then decide whether readmission to hospital is necessary. Gastro-intestinal haemorrhage, rapidly accumulating ascites, or deep coma are clear indications for immediate admission to hospital. If, on the other hand, the changes described above are recognized early, conservative management can be employed in the home. Improvement can be reasonably expected within 36 hours, and this may avert unnecessary readmission to hospital.

Next article on Emergencies in General Practice. “Pulmonary Embolism," by Professor R. B. Hunter.

\section{CHILD WELFARE CENTRE}

\section{"PROVINCE OF NATAL" WELFARE CENTRE OPENED IN LONDON}

The High Commissioner for the Union of South Africa (Mr. G. P. JoOSTE) on May 26 opened the "Province of Natal" Centre for Child Health in London. The centre is a handsome and spacious erection in Guilford Place, on the dividing border between the boroughs of Holborn and St. Pancras, and adjacent to the Hospital for Sick Children, Great Ormond Street. In addition to serving as a welfare centre, it is to house the Institute of Child Health, hitherto located at the hospital, and it seems to have a fair amount of space unallocated and available for future developments.
The ground floor is planned for maternity and child welfare work, with a hall for lectures and meetings, a kitchen for demonstrations, and a creche open on certain afternoons a week in which busy mothers may leave their children. The first floor is given over to school health work; and here all the activities of a school health service which are more conveniently carried out at a clinic than in the school itself will proceed. On this or the floor above there are a dental department, an orthoptic clinic, a clinic for minor ailments, an audiology room, and a child guidance centre, where a psychiatrist and psychiatric social worker will be engaged. Elsewhere in the building are two large laboratories and all their accessories. Special attention was drawn to the system of benches cantilevered from the wall and provided with continuous service racks, while each of the underbench units is independent and removable.

\section{A South African Benefaction}

At the opening ceremony Professor Alan Moncrieff, Director of the Institute of Child Health, explained how this new venture had come about. He reminded the company that the University of London Institute of Child Health was founded in 1946, with a generous gift from the Nuffield Foundation to establish a chair in child health and with the warm support of the university authorities on the one hand and the board of management and staff of the Hospital for Sick Children on the other. Investigations then began to be made into where and how a model welfare centre could be established. In 1947 the Mayor of Durban, Mr. Rupert Brown, came to London, and in an interview with Professor Moncrieff said how sorry he was that the National Health Service newly instituted in Britain prevented the people of Natal from helping Great Ormond Street. "I remember gripping my chair hard as I launched into a tactful explanation to him of how the money could still be used-for our model welfare centre." He had a dreadful feeling that he was too late, but fortunately the Mayor was convinced, the South African Gift Committee was communicated with, and before the end of the year a grant of $f 106,888 \mathrm{had}$ been made. Then ensued a period of planning and architects' conferences. The University had acquired land, a portion of which was available, and the London County Council signified its willingness to pay $90 \%$ of the cost of maintenance and all the salaries of medical and nursing staff. A house committee, with representatives of the L.C.C., the two borough councils from whose areas most of the children will be drawn, and the Institute of Child Health, will control general matters of policy, voluntary help, clinic sessions, amenities, and so forth. Professor Moncrieff added that it was a stipulation at the time of the original gift that the name "Province of Natal" should be associated with the centre.

The object was first to give a model service to the children of this part of London, and also as a university centre to undertake teaching and research. Postgraduate doctors and student nurses would come from Great Ormond Street to learn what was going forward, also health visitors, and it was hoped that the L.C.C. would use the centre in the training of their medical and nursing staffs.

The High Commissioner then formally declared the Centre open and unveiled a commemorative plaque. He explained that the financial assistance which came from the people of Natal was from a fund originally called the "Salute to Britain" fund, expressive of the deep feeling of sympathy for the people of Britain in their ordeal during the war. It was difficult to conceive a more fitting manner in which the money could have been used than in the construction of this Centre to alleviate suffering and promote knowledge in the service of children, in whom lay the future of any nation.

The thanks of the London County Council for the facilities provided by the centre were voiced by its chairman, Mr. NoRman Pritchard, and His Excellency was thanked by Lord WAVERLEY, chairman of the governing body of the British Postgraduate Medical Federation. 